\title{
Using Peripheral Stimulation to Reduce the Pain of C2-Mediated Occipital Headaches: A Preliminary Report
}

Eugene A. Melvin, Jr., MD ${ }^{1}$, F. Richard Jordan, $\mathrm{MD}^{2}$, Richard L. Weiner, $\mathrm{MD}^{3}$, and David Primm, $\mathrm{MA}^{4}$

From: ${ }^{1}$ Pain Center of Central Florida, Orlando, FL; ${ }^{2}$ St. Vincent Medical Center, Sherwood, AR; ${ }^{3}$ Presbyterian Hospital of Dallas, TX; ${ }^{4}$ Advanced Neuromodulation Systems. Dr. Melvin ${ }^{1}$ is also with Health Central Hospital, Ocoee, FL; and Orlando Center for Outpatient Surgery, Orlando, FL. Dr. Jordan ${ }^{2}$ is also with the Southwest Regional Medical Center, Little Rock, AR; and Arkansas Surgical Hospital,

Maumelle, AR. Dr. Weiner ${ }^{3}$ is also with Presbyterian Hospital of Plano, TX, Dallas Neurosurgical Associates, Dallas, TX; Baylor Hospital of Plano, TX; and Lake Pointe Medical Center of Rowlett, TX. Primm ${ }^{4}$ is with Advanced Neuromoduatlin Systems,

Inc, Plano, TX

Address Correspondence: Eugene A. Melvin, Jr., MD Pain Center of Central Florida 3861 Oakwater Circle, Suite 2 Orlando, FL 32806

E-mail: paininthenet@hotmail.com

Funding: Drs. Melvin, Jordan and Weiner were funded by ANS to perform the patient trials/implants. Conflict of interest: None. Manuscript received on: 08/01/2006 Revisions accepted: 09/11/2006 Accepted for publication on: $09 / 14 / 2006$

Free Full manuscript: www.painphysicianjournal.com
Background: Peripheral nerve stimulation (PNS) is an accepted treatment for neuropathic pain. Recent studies have focused on its potential for relieving headache pain

Objectives: To investigate the effectiveness of PNS in reducing occipital headache pain.

Design: A prospective, 12-week pilot study involving 11 patients evaluated before and after implantation of PNS systems to treat C2-mediated occipital headaches.

Methods: Prior to and at 4 and 12 weeks after implantation, patients completed the Short-Form McGill Pain Questionnaire (SF-MPQ), Visual Analog Scale (VAS), and Present Pain Index (PPI). Patients also answered questionnaires and kept diaries to record stimulator use, medication consumption, and numbers of headaches.

Results: A comparison of pre- and post-implantation evaluations showed statistically significant declines in scores on the SF-MPQ (64\%; $p=0.0013)$, VAS $(67 \% ; p<0.0001)$, and PPI (68\%; $p=0.0009)$. Most patients ( $91 \%$ and $64 \%$ respectively) reported reductions in medication use and numbers of headaches. Patients also reported a reduction in headache symptoms and the impact of headaches on activities. Two adverse events were encountered, one due to a loose connection and, the other caused by lead migration.

Conclusions: PNS reduced headache pain, headache frequency and medication use.

Key words: peripheral nerve stimulation, PNS, peripheral nerve, occipital headache, headache pain

Pain Physician 2007; 10:453-460 
$D$ eripheral nerve stimulation has been used for more than 30 years to relieve chronic pain (1). While the potential of PNS as a painrelief method has been recognized, early usage was hampered by technical limitations and insufficient surgical techniques. As a result, PNS was not widely used until the progress of spinal cord stimulation (SCS) technologies and empirical data supporting the effectiveness of SCS persuaded clinicians to expand the use of PNS to control intractable pain (2).

Part of the therapy's appeal is due to its limited risks for patients. PNS, like other neurostimulation methods, is minimally invasive and reversible. It also allows patients to test its effectiveness in a trial procedure before committing to a permanent implant. As a result, PNS has been used to treat pain caused by a number of conditions, including posttraumatic neuropathy, diabetic neuropathy, and chronic pelvic pain $(3,4)$. It has also been effective in reducing pain in patients with severe reflex sympathetic dystrophy (RSD, also known as CRPS I) that is limited to a single nerve distribution (5). The process by which PNS inhibits pain in such conditions is not completely understood. However, studies indicate that PNS leads to an inhibitory input within the pain pathways of the spinal cord (6).

One of the newest and most promising applications of PNS is for headache pain. PNS has helped relieve the pain occipital neuralgia and transformed migraine (7). Similarly, C1 through C3 PNS has been used for disabling transformed migraines, helping to reduce disability and number of headache days (8). Other research has shown that C1 PNS reduces the pain of patients with intractable occipital neuralgia (9). The purpose of this study is to further investigate PNS's ability to relieve headache pain by examining how well PNS reduces the pain of C2-mediated occipi- tal headaches.

\section{Study Design}

This study was approved by the Institutional Review Board (IRB) of Copernicus Group through Health Central Hospital, Ocoee, Florida. Written informed consent was obtained from the participants. The initiation date of this study was $1 / 11 / 01$ and the close date was $8 / 8 / 02$. This prospective, 12 -week pilot study was designed to enroll a small number of patients to investigate the efficacy of PNS in controlling C2-mediated occipital headaches. Patients were recruited nonrandomly and met enrollment criteria in order to join the study (Table 1). Those patients who responded positively to a subsequent stimulation trial were later implanted with a permanent PNS system. Baseline measures provided by patients prior to implantation were compared with the same measures taken at 4 and 12 weeks post-implantation. All data was collected by clinic personnel.

\section{Baseline and Post-Implant Measurements}

Patients who were enrolled in the study provided baseline information about their headache pain at 2 times during the study: at the initial visit with clinical staff that determined eligibility to join the study, and at a subsequent visit that took place after the stimulation trial but before implant surgery. The baseline measurements consisted of the patients' responses to the following pain evaluators:

- A Short-Form McGill Pain Questionnaire (SF-MPQ)

- A headache questionnaire

- A headache diary

The SF-MPQ consisted of 15 representative words

Table 1. Enrollment criteria

\begin{tabular}{|l|l|}
\hline Patients must have had & Patients could not have \\
\hline • C2-mediated occipital headache pain for more than 6 months & • A diagnosis of a terminal disease \\
\hline • Extracranial tenderness or Tinel's sign over the occipital nerve & • Been a participant in a concurrent study involving an investigational device \\
\hline - A positive response to occipital nerve blocks & • A likelihood of requiring MRI evaluations in the future \\
\hline $\begin{array}{l}\text { • Poor responses to other medical treatments (e.g., narcotics, } \\
\text { physical therapy) }\end{array}$ & $\begin{array}{l}\text { • A cervical MRI or upper cervical CT scan that showed an identifiable } \\
\text { abnormality }\end{array}$ \\
\hline • A Visual Analog Scale (VAS) score of at least 6 & $\begin{array}{l}\text { • A diagnosis of a personality disorder or psychosis (such as substance abuse } \\
\text { or paranoid disorders) }\end{array}$ \\
\hline & $\begin{array}{l}\text { • A demand-type cardiac pacemaker } \\
\text { • Been pregnant (confirmed by positive urine pregnancy test), nursing a } \\
\text { child, or using inadequate contraception (females) }\end{array}$ \\
\hline
\end{tabular}


from sensory and affective categories that patients used to describe their pain level. This evaluator also included a VAS and Present Pain Index (PPI). The PPI was composed of number-word combinations that patients selected to indicate their pain intensity.

The headache questionnaire was created for this study and was based on established questionnaires for headaches $(10,11)$. It contained questions that asked patients about the intensity of their pain, the number of symptoms they were experiencing, and the degree to which pain was interfering with their work and other activities. Besides this questionnaire, patients filled out a headache diary that required them to record the amount of pain medication they consumed, the number of headaches they experienced, and how much they were using their stimulators. Patients were asked to take the diary home with them and fill it out before returning it at their next visit to their clinical site. Diary information was used to draw basic conclusions about the patients' medication use and number of headaches (i.e., whether these items had increased/decreased). The patients' highest scores on all the baseline evaluators, taken from either of the 2 baseline visits, were later compared to the patients' responses to these same evaluators at 4 and 12 weeks post implant (Table 2). At 4 and 12 weeks, patients also answered questions relating to satisfaction and device use. During the post-implant period, data were collected on the patients' programming, adverse events, and the relationship between their number of leads and their evaluator scores.

\section{Stimulation Trial}

Approximately 4 weeks after being enrolled in the study, each patient was given a PNS stimulation trial. This involved implanting the patient with a percutaneous trial lead that was connected to an external power source, both of which were used to stimulate the patient's occipital nerves. Patients took these systems home with them for 4-10 days, during which they observed how their pain responded to stimulation. At the end of the trial, patients returned to their clinical sites for evaluation and filled out VAS forms. If a patient received continuous and significant pain control from stimulation and had at least a $50 \%$ reduction in VAS scores compared to baseline scores, the patient was scheduled for surgery to receive a permanent PNS system.

\section{IMPLANT SURGERY}

\section{Device Description}

The PNS system implanted into patients consisted of 2 main parts: a percutaneous lead(s) and implantable pulse generator (IPG). All leads and IPGs were manufactured by ANS (Advanced Neuromodulation Systems, Inc., Plano, TX). Patients received either 1 lead containing 8 electrodes (Octrode lead model 3086,3186 , or 3183) or 2 leads containing 4 electrodes each (Quattrode lead model 3046, 3156, or 3153). The IPG was an 8-channel programmable device that provided electrical stimulation (Genesis IPG model 3608).

\section{Implant Procedure}

Each patient received the implant under local anesthesia. A small vertical incision was made at the lev-

Table 2. Data collection schedule

\begin{tabular}{|c|c|c|c|c|c|c|}
\hline & $\begin{array}{l}\text { First baseline } \\
\text { visit }\end{array}$ & $\begin{array}{l}\text { Stimulation } \\
\text { trial }\end{array}$ & $\begin{array}{l}\text { Second baseline } \\
\text { visit }\end{array}$ & $\begin{array}{l}\text { Implant } \\
\text { surgery }\end{array}$ & 4-week visit & 12-week visit \\
\hline Time (approx.) & $\begin{array}{l}4 \text { weeks before } \\
\text { stim trial }\end{array}$ & & $\begin{array}{l}\text { After stim trial, } \\
\text { prior to implant } \\
\text { surgery }\end{array}$ & & $\begin{array}{l}4 \text { weeks after } \\
\text { implant surgery }\end{array}$ & $\begin{array}{l}12 \text { weeks after } \\
\text { implant surgery }\end{array}$ \\
\hline Measures taken & $\begin{array}{l}\text { SF-MPQ } \\
\text { headache } \\
\text { questionnaire } \\
\text { headache diary }\end{array}$ & $\begin{array}{l}\text { VAS } \\
\text { headache diary }\end{array}$ & $\begin{array}{l}\text { SF-MPQ } \\
\text { headache } \\
\text { questionnaire } \\
\text { headache diary }\end{array}$ & headache diary & $\begin{array}{l}\text { SF-MPQ } \\
\text { headache } \\
\text { questionnaire } \\
\text { headache diary } \\
\text { satisfaction and } \\
\text { use questions }\end{array}$ & $\begin{array}{l}\text { SF-MPQ } \\
\text { headache } \\
\text { questionnaire } \\
\text { satisfaction and } \\
\text { use questions }\end{array}$ \\
\hline
\end{tabular}


el of the patient's C1 lamina in an area either medial and inferior to the mastoid process or in the midline posterior. Subcutaneous tissue immediately lateral to the incision was undermined with sharp scissors so that it might accept a loop of electrode lead to keep the lead from migrating. A Tuohy needle was curved to conform to the transverse cervical curvature (bevel inwards), and without further dissection, the needle was passed into the subcutaneous space across the base of the targeted occipital nerves. At the C1 level, these nerves are located within the cervical musculature and overlying fascia.

The needle was used to place the lead(s). Afterwards, the needle was withdrawn and the lead was connected to a stimulation device in order to conduct intraoperative tests. The tests confirmed that the lead was in the right place and that the patient was experiencing paresthesia when the lead's electrodes were stimulated. After the tests, the lead was secured with lead anchors and sutures.

Next, the IPG was placed into a subcutaneous pocket that was created in the abdomen or infrascapular region. The pocket was parallel to the skin and not more than $4 \mathrm{~cm}$ below it. A tunneling tool was used to create a subcutaneous tunnel between the lead incision and the IPG pocket, and the lead was threaded down the tunnel to connect it to the IPG, after which the incisions were closed.

The patients' IPGs were programmed immediately after surgery to relieve pain. About 2 weeks after surgery, patients returned to their clinical sites to make sure they had recovered and to ensure that the programming of their IPGs was optimal. The IPG could be reprogrammed as needed by designated staff during subsequent visits to the clinical site.

\section{Results}

All statistical significance data was produced by 2-sided paired t-tests unless otherwise indicated.

\section{Patient Information}

\section{Patient Enrollment}

A total of 16 patients were screened for the study, and 11 were enrolled. The 5 patients who were not enrolled were unable to join the study for a number of reasons, including the failure of their stimulation trial (Table 3).
Table 3. Patient enrollment

\begin{tabular}{|l|l|}
\hline Patients enrolled in study & 16 \\
\hline Patients who completed study & 11 \\
\hline $\begin{array}{l}\text { Reasons for not completing study } \\
\text { (no. of patients) }\end{array}$ & $\begin{array}{l}\text { failure of stimulation trial (3) } \\
\text { drug-seeking behavior (1) } \\
\text { chose to not to participate (1) }\end{array}$ \\
\hline
\end{tabular}

Table 4. Demographics

\begin{tabular}{|l|l|}
\hline Gender & 9 female, 2 male \\
\hline Mean age (range) & 47.3 years (36-65 years) \\
\hline Mean weight (range) & $\begin{array}{l}\text { male-230 lbs. (184-276 lbs.) } \\
\text { female-163 lbs. (135-190 lbs.) }\end{array}$ \\
\hline Cause of pain (no. of patients) & $\begin{array}{l}\text { motor vehicle accident (3) } \\
\text { blow to head (1) } \\
\text { falling accident (1) } \\
\text { medical procedure (1) } \\
\text { didn't know (5) }\end{array}$ \\
\hline $\begin{array}{l}\text { Mean length of time with pain } \\
\text { (range) }\end{array}$ & 3.4 years (1 - 7 years) \\
\hline $\begin{array}{l}\text { Prior pain treatments (no. of } \\
\text { patients) }\end{array}$ & $\begin{array}{l}\text { oral analgesics (11) } \\
\text { steroid injections (11) } \\
\text { anesthetic blocks (8) }\end{array}$ \\
\hline $\begin{array}{l}\text { Mean no. of physicians that } \\
\text { patients had visited (range) }\end{array}$ & 3.2 (3-20) \\
\hline $\begin{array}{l}\text { Patients using oral analgesics } \\
\text { at start of study }\end{array}$ & 10 \\
\hline $\begin{array}{l}\text { Implant received by patients } \\
\text { (no. of patients) }\end{array}$ & $\begin{array}{l}\text { IPG with single octopolar lead (7) } \\
\text { IPG with dual quadripolar leads (4) }\end{array}$ \\
\hline
\end{tabular}

\section{Demographics}

Most of the patients who completed the study were female and had been experiencing headache pain for a number of years (Table 4). Prior to their implant procedure, the patients had received standard pain treatments that included oral analgesics, steroid injections, and nerve blocks. Almost all of the patients were using narcotic or non-narcotic analgesic medications to control their pain at the start of the study.

\section{IPG Programming}

After surgery, patients were given one or more stimulation programs to use. Eight patients were given a single program, 2 were given 2 programs, and 1 was given 3 programs. The 2 main programs had varying 
parametric ranges (Table 5). Patients had some control over their stimulation provided by their IPGs. They could turn the IPG on and off and adjust its amplitude or stimulation pattern. All patients continued to take their oral medications while using their IPGs.

\section{Evaluator Scores}

\section{SF-MPQ, VAS, and PPI}

The patients experienced significant declines in their scores on the SF-MPQ and its accompanying VAS and PPI evaluators between the baseline and 4 and 12 weeks visits (Table 6). Declines were also observed when the SF-MPQ's sensory and affective questions were considered separately. At 12 weeks, these declines translated into $p$ values that had high significance levels, with no value being greater than 0.0062 . Overall, the scores on the evaluators fell $61-71 \%$ during the study.

\section{Headache Questionnaire}

The patients' scores on headache questionnaire items declined between the baseline period and 4 and 12 weeks. Scores on many items suggested that patients were experiencing declines in their pain intensity and the degree to which headaches were interfer- ing with work and other activities (Table 7).

The headache questionnaire also allowed patients to report how often they experienced common symptoms with their headaches, including pulsating, unilateral, or exacerbating (extremely unpleasant) pain, sensitivity to sound and light, and nausea. The questionnaire allowed patients to indicate that these symptoms never occurred, occurred less than half the time, or occurred more than half the time. The number of symptoms that patients reported as having occurred more than half the time at baseline was reduced by $45 \%$ at 12 weeks. Correspondingly, the number of symptoms that patients said were never occurring grew as well, and by 12 weeks this number was $60 \%$ greater than that of the baseline period.

\section{Headache Diaries}

Table 5. Parametric ranges for programs

\begin{tabular}{|c|c|c|l||}
\hline & $\begin{array}{l}\text { Pulse width } \\
\text { (mean) }\end{array}$ & Frequency & Amplitude \\
\hline Program 1 & $\begin{array}{c}143-494 \mu \mathrm{s} \\
(236.6)\end{array}$ & $\begin{array}{c}30-100 \mathrm{~Hz} \\
(68.9)\end{array}$ & $1.9-10.5 \mathrm{~mA}(4.7)$ \\
\hline Program 2 & $208 \mu \mathrm{s}$ & $\begin{array}{c}30-50 \mathrm{~Hz} \\
(36.7)\end{array}$ & $2.3-6.75 \mathrm{~mA}(4.3)$ \\
\hline
\end{tabular}

Table 6. Mean SF-MPQ, VAS, and PPI results

\begin{tabular}{|l|c|c|c|c|c|}
\hline \hline & Baseline & 4 weeks & 12 weeks & \% change (12 weeks) & p value (12 weeks) \\
\hline SF-MPQ & 24.6 & 11.1 & 8.9 & -64 & $=0.0013$ \\
\hline SF-MPQ sensory & 18.1 & 8.7 & 7.0 & -61 & $=0.0010$ \\
\hline SF-MPQ affective & 6.6 & 2.4 & 1.9 & -71 & $=0.0062$ \\
\hline VAS & 9.3 & 3.7 & 3.1 & -67 & $<0.0001$ \\
\hline PPI & 3.6 & 1.5 & 1.2 & -67 & $=0.0009$ \\
\hline
\end{tabular}

Table 7. Mean responses (1-10 scale) to headache questionnaire items

\begin{tabular}{|l|c|c|c|c||}
\hline & Baseline & 4 weeks & 12 weeks & \% change (12 weeks) \\
\hline Intensity of current headache & 6.9 & 4.2 & 3.8 & -45 \\
\hline Average intensity of headaches & 8.9 & 5.7 & 7.2 & -19 \\
\hline Intensity of worst headaches & 10.0 & 7.6 & 8.5 & -15 \\
\hline Average intensity of worst headaches & 9.9 & 7.7 & 8.1 & -18 \\
\hline How much headaches interfered with daily activities & 8.5 & 4.3 & 5.6 & -34 \\
\hline $\begin{array}{l}\text { How much headaches interfered with recreational, social, } \\
\text { and family activities }\end{array}$ & 9.1 & 4.1 & 5.9 & -35 \\
\hline How much headaches reduced ability to work & 9.1 & 4.1 & 5.5 & -40 \\
\hline
\end{tabular}


Patients used 7-day diaries to report how much they used their stimulators, the number of headaches they were having each day, and how much medication they were consuming. By the end of the study, patients reported varying daily usages for their stimulator (Fig 1), and most patients reported declines in their number of headaches compared to baseline (Fig 2). Nearly all patients had decreased their consumption of oral pain medications by 12 weeks (Fig 3).

\section{Satisfaction}

Twice during the study, at 4 and 12 weeks, patients were asked questions relating to satisfaction and pain relief. One of the questions asked patients to rate their overall pain relief. At 4 weeks, $46 \%$ of patients rated this relief as excellent, $36 \%$ rated it as good, and $18 \%$ rated it as poor. At 12 weeks, no patient rated their relief as poor (Fig 4).

Patients were also asked if they thought the implant procedure was worth undergoing and whether they would recommend

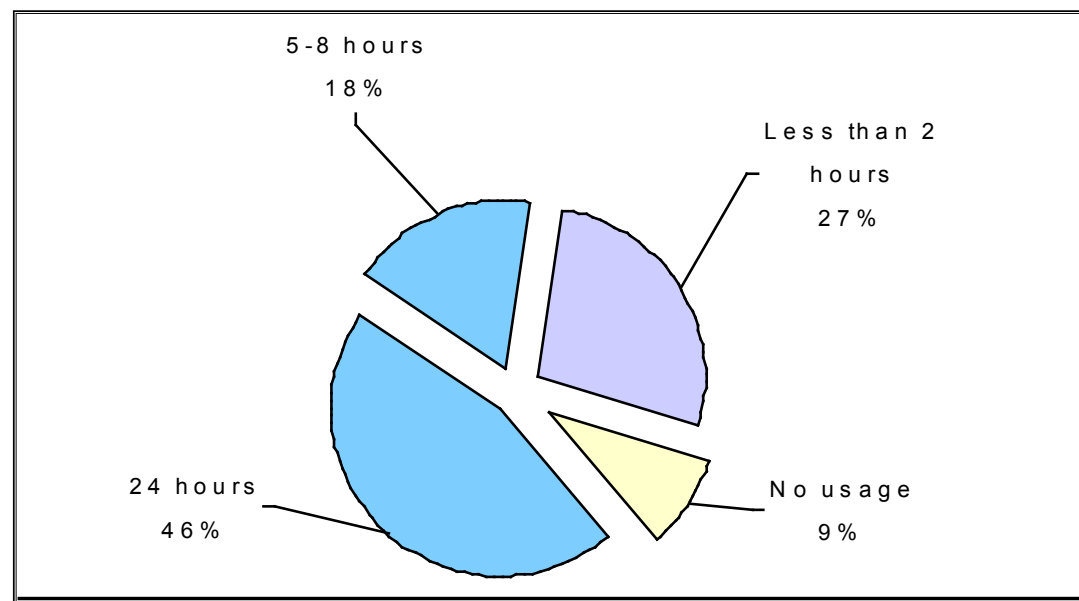

Fig. 1. Patients' daily usage of stimulators.

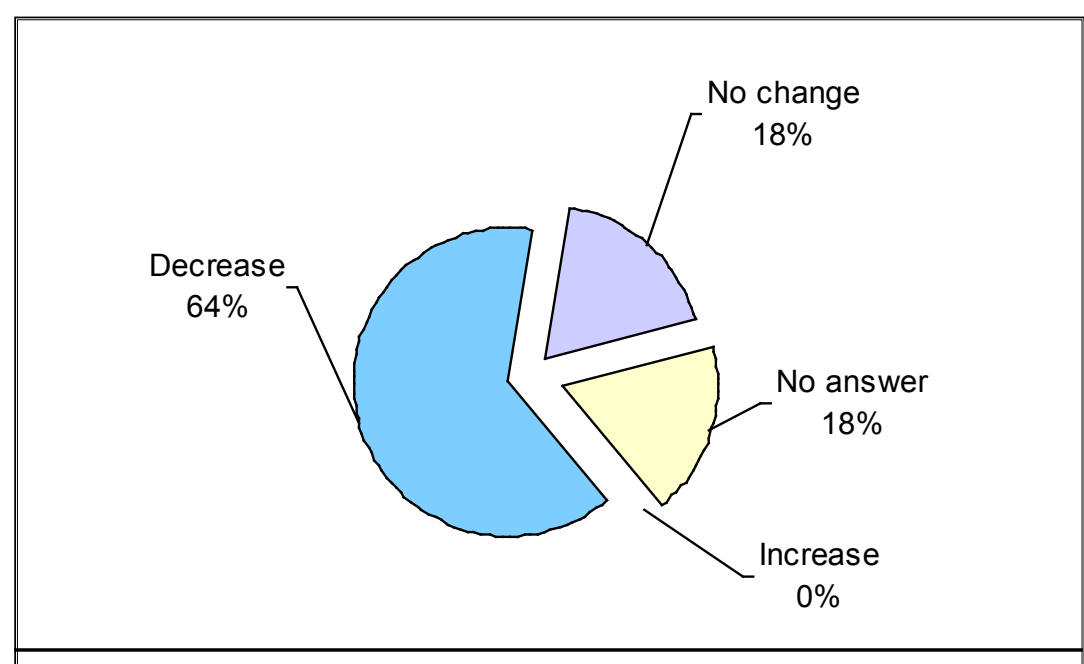

Fig. 2. Patients experiencing a change in number of headaches.

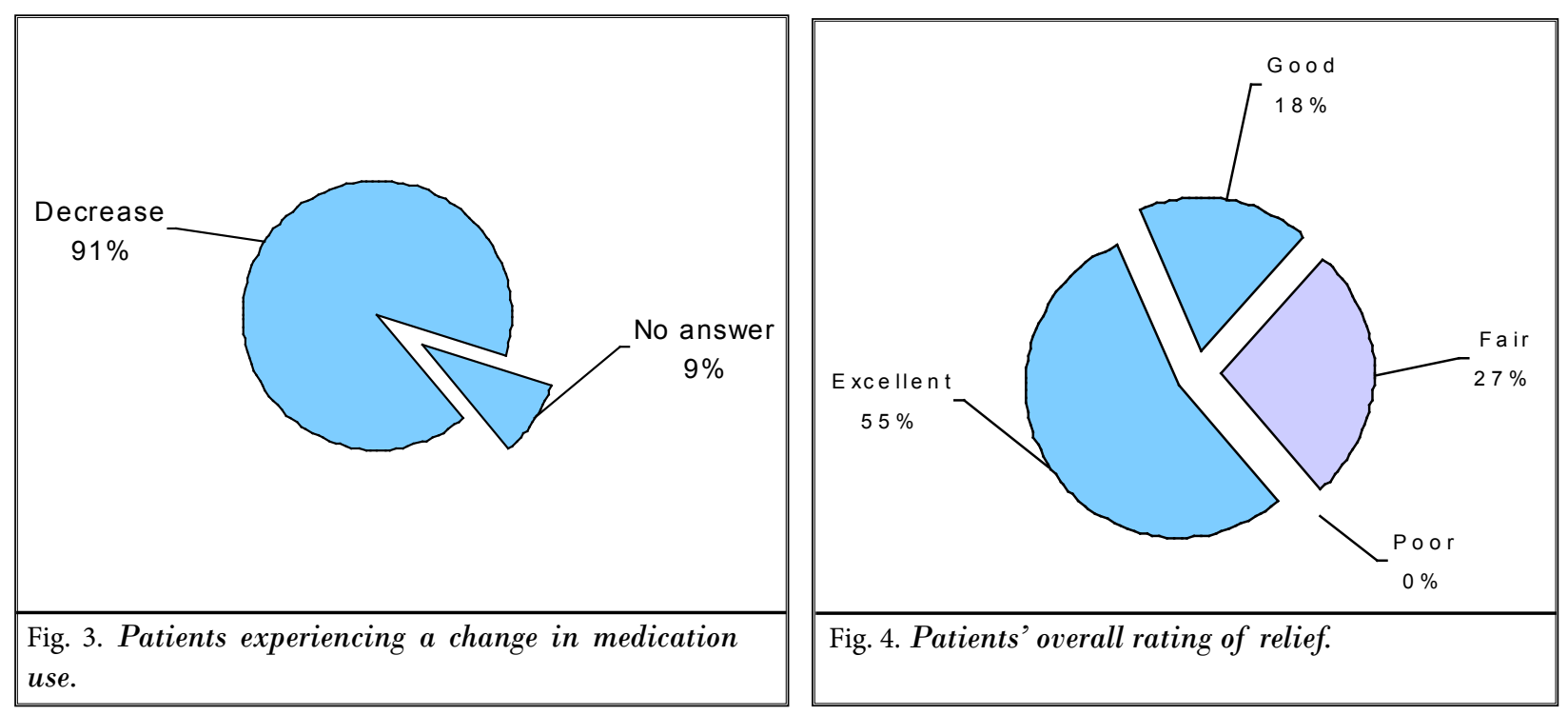


it to a friend or relative. At 4 weeks, 10 patients said the procedure was worth undergoing and would recommend it. At 12 weeks, all patients gave a positive response to this question.

\section{Number of Leads}

Seven patients in the study received a single lead with 8 electrodes, and 4 received 2 leads with 4 electrodes each. SF-MPQ, VAS, and PPI scores were analyzed for these 2 groups. No significant difference was found between the scores of patients with one lead and those of patients with 2 leads.

\section{Adverse Events}

Two adverse events were encountered during the study. One patient temporarily lost stimulation due to a loose connection. This problem was corrected by adding an extension to the patient's lead, after which stimulation was restored. Another patient experienced unwanted stimulation in her neck that caused her to have muscle spasms. Her lead was found to have migrated, and after it was repositioned, her stimulation was restored. Neither patient suffered residual effects after these corrective procedures.

\section{Discussion}

Patients were asked to fill out 5 headache diaries during the study. This method of data collection proved to be problematic. Patients sometimes did not follow diary instructions or left parts of their diaries incomplete or wrote illegibly. It appears that some patients avoided making daily entries in their diaries and instead filled out multiple entries just prior to their visits. In all, investigators found the diaries hard to assess and had questions about their accuracy.

Another challenge related to finding an established questionnaire that measured chronic headaches. Most headache questionnaires are targeted at migraine patients and have questions that refer to relatively short time periods. For this reason, this study's questionnaire was a combination of existing, non-chronic headache questionnaires that the investigators felt were likely to measure changes in the patients' pain. The patients' responses to the questionnaire confirmed that they were experiencing a beneficial effect from stimulation. However, these responses did not necessarily correspond to the pa- tients' responses to SF-MPQ, VAS, and PPI evaluators. A correlation analysis was performed to compare the responses to questionnaire items with the total scores on each evaluator. The analysis showed that the questionnaire responses were not strongly correlated with evaluator scores (no correlations greater than 0.57 ).

The majority of patients in this study were female, possibly because more females were referred to the study than males. This suggests the need for research concerning whether gender affects diagnosis or treatment outcomes for headache patients. The research could also investigate whether occipital nerve stimulation has differing effects for persistent and intermittent headaches. Another area for future research involves lead configurations and implantation methods. Seven patients received single leads implanted through a lateral incision in the neck, with the lead covering both occipital nerves. One patient's lead migrated when implanted this way. Four patients received dual leads implanted through the midline, with each lead placed on an occipital nerve near the start of the midline. One physician thought that this latter method provided better anchoring of the leads and could minimize migration.

Overall, the data in this study suggests that PNS has a strong positive effect on occipital headache pain and symptoms. This statement must be tempered by the study's limitations; its design lacked randomized patient selection and a control group, and its data were collected by clinical staff rather than an independent third party, which could have influenced the patients' responses. Still, the study adds to evidence regarding PNS's ability to reduce headache pain and shows the desirability of conducting controlled studies to more fully investigate the potential of this therapy. Patients in the study reported significant declines in pain on SF-MPQ, VAS, and PPI evaluators and reported declines in accompanying symptoms and the degree to which headaches kept them from activities. Such findings indicate that PNS may provide physicians with a valuable option for treating intractable occipital headaches.

\section{Conclusions}

PNS appeared effective in reducing the headache pain and symptoms for patients with C2-mediated occipital headaches. PNS also resulted in the patients reporting that they used less medication, had fewer headaches, and that their headaches had less of an impact on their activities. 


\section{References}

1. Wall PD, Sweet WH. Temporary abolition of pain in man. Science 1967; 155:108109.

2. Stanton-Hicks M, Salamon J. Stimulation of the central and peripheral nervous system for the control of pain. J Clin Neurophysio 1997; 14:46-62.

3. Campbell IN, Long DM. Peripheral nerve stimulation in the treatment of intractable pain. J Neuro Surg 1976; 45:692699.

4. Stojanovic MP. Stimulation methods for neuropathic pain control. Current Pain and Headache Reports 2001; 5:130-137.

5. Hassenbusch SJ, Stanton-Hicks
Schoppa D, Walsh JG, Covington EC. Long-term results of peripheral nerve stimulation for reflex sympathetic dystrophy. J Neurosurg 1996; 84:415-423.

6. Hanai F. Effect of electrical stimulation of peripheral nerves on neuropathic pain. Spine 2000; 25:1886-1892.

7. Oh MY, Ortega J, Bellotte J, Whiting DM, Alo K. Peripheral nerve stimulation for the treatment of occipital neuralgia and transformed migraine using a $\mathrm{C}_{1}$ 2-3 subcutaneous paddle style electrode: a technical report. Neuromodulation 2004; 7:103-112.

8. Popeney CA, Aló KM. Peripheral neuro- stimulation for the treatment of chronic, disabling transformed migraine. Headache 2003; 43:369-375.

9. Weiner RL, Reed KL. Peripheral neurostimulation for control of intractable occipital neuralgia. Neuromodulation 1999; 2:217-221.

10. Von Korff M, Stewart WF, Lipton RB. Assessing headache severity. Neurology 1994; 44:S40-S46.

11. Stewart WF, Lipton RB, Simon D Liberman J, Von Korff M. Validity of an illness severity measure for headache in a population sample of migraine sufferers. Pain 1999; 79:291-301. 